BMJ Open

Diabetes

Research

\& Care

\section{Perceived diabetes risk and related determinants in individuals with high actual diabetes risk: results from a nationwide population-based survey}

\author{
Christin Heidemann, ${ }^{0}$ Rebecca Paprott, ${ }^{1}$ Lena M Stühmann, ${ }^{1,2}$ Jens Baumert, ${ }^{1}$ \\ Kristin Mühlenbruch, ${ }^{\circ}$ Sylvia Hansen, ${ }^{\oplus 4}$ Catarina Schiborn, ${ }^{3}$ Daniela Zahn, ${ }^{4}$ \\ Paul Gellert, ${ }^{2}$ Christa Scheidt-Nave ${ }^{1}$
}

To cite: Heidemann C, Paprott R, Stühmann LM, et al. Perceived diabetes risk and related determinants in individuals with high actual diabetes risk: results from a nationwide population-based survey. BMJ Open Diab Res Care 2019;7:e000680. doi:10.1136/ bmjdrc-2019-000680

Received 28 March 2019 Revised 26 April 2019 Accepted 16 May 2019

Check for updates

C Author(s) (or their employer(s)) 2019. Re-use permitted under CC BY-NC. No commercial re-use. See rights and permissions. Published by BMJ.

${ }^{1}$ Department of Epidemiology and Health Monitoring, Robert Koch Institute, Berlin, Germany ${ }^{2}$ Institute of Medical Sociology, Charité-Universitätsmedizin, Berlin, Germany ${ }^{3}$ Department of Molecular Epidemiology, German Institute of Human Nutrition PotsdamRehbruecke, Nuthetal, Germany ${ }^{4}$ Office for National Education and Communication on Diabetes mellitus, Federal Centre for Health Education, Cologne, Germany

Correspondence to Dr Christin Heidemann; HeidemannC@rki.de

\section{ABSTRACT} perceived diabetes risk compared with actual diabetes risk in the general population and second, to investigate which factors determine whether persons at increased actual risk also perceive themselves at elevated risk.

Research design and methods The study comprised adults (aged 18-97 years) without known diabetes from a nationwide survey on diabetes-related knowledge and information needs in Germany in 2017. Actual diabetes risk was calculated by an established risk score estimating the 5-year probability of developing type 2 diabetes and was compared with perceived risk of getting diabetes over the next 5 years (response options: 'almost no risk', 'slight risk', 'moderate risk', 'high risk'; $n=2327$ ). Among adults with an increased actual diabetes risk $(n=639)$, determinants of perceived risk were investigated using multivariable logistic regression analysis.

Results Across groups with a 'low' $(<2 \%)$, 'still low' ( $2 \%$ to $<5 \%)$, 'elevated' $(5 \%$ to $<10 \%)$, and 'high' $(\geq 10 \%)$ actual diabetes risk, a proportion of $89.0 \%, 84.5 \%, 79.3 \%$, and $78.9 \%$, respectively, perceived their diabetes risk as almost absent or slight. Among those with an increased (elevated/high) actual risk, independent determinants of an increased (moderate/high) perceived risk included younger age ( $0 \mathrm{R} 0.92$ ( $95 \% \mathrm{Cl} 0.88$ to 0.96$)$ per year), family history of diabetes $(2.10(1.06-4.16))$, and being informed about an increased diabetes risk by a physician (3.27 (1.51-7.07)), but none of further diabetes risk factors, healthcare behaviors or beliefs about diabetes.

Conclusions Across categories of actual diabetes risk, perceived diabetes risk was low, even if actual diabetes risk was high. For effective strategies of primary diabetes prevention, attention should be directed to risk communication at the population level as well as in primary care practice.

\section{INTRODUCTION}

Type 2 diabetes and its complications can lead to disability and premature death in affected individuals, cause enormous costs for healthcare systems and thus, represent a major public health challenge for most countries across the globe. ${ }^{12}$ In addition to the high
Objective The purpose of this study was first, to examine

\section{Significance of this study}

What is already known about this subject?

- Some previous studies observed a slightly higher perceived diabetes risk with higher actual diabetes risk. However, an underestimation of risk seems to be evident among persons with a high-risk profile.

- Determinants that might explain the discrepancy between perceived and actual diabetes risk among high-risk individuals, who are an important target group for primary prevention, have scarcely been investigated.

\section{What are the new findings?}

- The current nationwide data reflect a relatively low perception of diabetes risk in the general adult population in Germany, even if actual diabetes risk measured by a multifactorial risk score is high.

- Focusing on adults with an increased actual diabetes risk revealed that besides younger age and family history of diabetes, being informed about an increased diabetes risk by a physician was strongly and independently related to a higher risk perception.

- In contrast, potentially modifiable risk factors of diabetes, preventive healthcare behaviors, and psychological factors such as beliefs in general and personal control of diabetes risk seemed to play no determining role for perceived risk.

\section{How might these results change the focus of} research or clinical practice?

- The findings could inform the strategic orientation of diabetes prevention strategies by emphasizing the need to raise the awareness of diabetes risk and also highlight the importance of effective risk communication between health professionals and patients at elevated diabetes risk.

burden of diagnosed diabetes, most countries face a considerable number of people with undiagnosed diabetes ${ }^{3}$ along with a high number of people with prediabetes that are 
at high risk for future diabetes. ${ }^{4}$ In USA, for example, at least one in five adults with diabetes is undiagnosed and about a third of the adult population has prediabetes. ${ }^{5}$

To tackle the growing burden from diabetes and its antecedents, implementation of primary prevention approaches aiming at risk factor control through behavioral and environmental changes is regarded as an essential cornerstone. ${ }^{6} 7$ Indeed, several randomized clinical trials succeeded in reducing the progression from prediabetes to diabetes by lifestyle modifications. ${ }^{8}$ However, for primary prevention measures to be effective in a real world setting, people, especially those with a high-risk profile, need to be aware of their risk of developing a disease. $^{910}$

Some previous studies suggested that a higher actual risk defined by measured glycemic status or multifactorial risk scores is associated with a slightly higher perceived risk. ${ }^{11-17}$ However, among persons with high actual diabetes risk, an underestimation of risk seems to be evident. ${ }^{11-1518} 19$ For the development of effective risk communication strategies, it is therefore important to recognize factors that might explain this discrepancy. So far, only few studies have addressed this question and consistently found that among considered sociodemographic and diabetes risk factors, lower age and a family history of diabetes were related to a higher risk perception in persons at high actual risk. ${ }^{11} 1218$ However, these studies were confined to middle-aged or elderly adults living in geographically small areas and did not include factors such as risk communication by the physician or diabetes-related control beliefs, which could potentially also be related to perceived risk.

Against this background, the aims of the study were first, to evaluate perceived diabetes risk in comparison to actual diabetes risk in a representative sample of the general adult population and second, to investigate whether sociodemographic and diabetes risk factors as well as healthcare and psychological factors contribute to explain diabetes risk perception in the subgroup of adults at high actual diabetes risk.

\section{RESEARCH DESIGN AND METHODS}

Study on "Disease knowledge and information needs Diabetes mellitus (2017)"

A national telephone interview survey focusing on diabetes-related knowledge, perceptions, and information needs was conducted by the Robert Koch Institute between September and November 2017 as previously described in detail. ${ }^{20}$ In brief, landline and mobile telephone numbers were randomly generated to assure that over the phone reachable private households were representatively considered for the study. In a next step, a Kish selection grid was applied for random sampling of adult German-speaking household members (aged at least 18 years) for interview. Computer-assisted interviews were performed by trained personnel based on separate questionnaires for persons without and with diagnosed diabetes. By this random sampling procedure, 2590 persons ( $n=2327$ without and $n=263$ with self-reported diagnosed diabetes) were included. The response rate calculated as a proportion of conducted interviews in relation to private households theoretically reachable over the phone (ie, response rate 3 according to the criteria of the American Association for Public Opinion Research) was $17.9 \% .^{21}$ In a further step, a direct screening procedure for persons with diagnosed diabetes was applied to gain a larger subsample for diagnosed diabetes. Only in the case of more than one person with diagnosed diabetes in a household, a Kish selection grid was used to randomly select the household member for interview. By this screening procedure, 1216 persons with self-reported diagnosed diabetes were interviewed. Thus, the final study sample comprised 3806 participants $(n=2327$ without self-reported diagnosed diabetes aged 18-97 years and $n=1479$ with self-reported diagnosed diabetes aged 18-96 years). All participants were informed at the beginning of the telephone interview about the voluntary nature of their participation, the objectives of the survey as well as data protection and gave their informed consent to participate verbally.

\section{Study population}

For descriptive analyses, all 2327 participants without diagnosed diabetes were included. For logistic regression analyses that specifically focused on participants with an elevated or high actual diabetes risk, 639 participants with an actual diabetes risk $\geq 5 \%$ were considered.

\section{Assessment of actual 5-year diabetes risk}

Actual diabetes risk was defined by the German Diabetes Risk Score (GDRS) that estimates the 5-year probability of developing type 2 diabetes. ${ }^{22}$ The updated and validated simplified GDRS version was applied that considers age, waist circumference, body height, physical activity, smoking, history of hypertension, family history of diabetes, red meat intake, wholegrain intake, and coffee consumption as categorical score components. ${ }^{23} 24$

In the current survey, physical activity was assessed by asking whether participants are usually physically active $\geq 5$ hours per week, also including sport, gardening, and cycling. Smoking habit was assessed by asking for current and former smoking as well as the average number $(<20$ or $\geq 20)$ of cigarettes, cigarillos, or cigars smoked per day. History of hypertension was obtained by asking whether participants ever had a diagnosis of hypertension. Family history of diabetes was assessed by asking for a diabetes diagnosis in one or both biological parents, or in at least one biological sibling. Red meat intake was assessed as frequency of consumption of beef, pork, and lamb (ranging from never or rarely to several times a day). Whole grain intake was obtained as sum of consumed slices of whole grain bread, whole grain rolls, and portions of muesli (3 table 
spoons per portion) per day. Coffee consumption was assessed as cups of coffee (including espresso, cappuccino, latte macchiato) per day. Waist circumference was not assessed in the current survey and therefore, was estimated based on self-reported body weight (in $\mathrm{kg}$ ), body height (in $\mathrm{cm}$ ), age, and sex using the following equations:

Waist circumference for men $=93.4692084$ $0.4147528 *$ height $(\mathrm{cm})+0.7517554 *$ weight $(\mathrm{kg})$ $+0.2589500 *$ age (years)

Waist circumference for women $=82.4905304$ $0.3990789 *$ height $(\mathrm{cm})+0.8359074 *$ weight $(\mathrm{kg})$ $+0.1983362 *$ age (years)

The authors derived equations from linear regression analysis based on data from the nationally representative German Health Interview and Examination Survey for Adults $(2008-2011)^{25}$ with waist circumference measured by trained health professionals as the dependent variable and age and self-reported body weight and height as independent variables.

Based on the previously published algorithm, points were assigned to each GDRS component to calculate actual diabetes risk. ${ }^{23}$ For the current analysis, actual diabetes risk was categorized into $<2 \%$ ('low risk'), $2 \%$ to $<5 \%$ ('still low risk'), $5 \%$ to $<10 \%$ ('elevated risk'), and $\geq 10 \%$ ('high') following the currently used classification for risk communication of GDRS test results. ${ }^{26}$

\section{Assessment of perceived 5-year diabetes risk and potential determinants \\ Perceived diabetes risk}

Perceived diabetes risk was assessed by the question "What do you think is your risk for getting diabetes over the next 5 years?" (response options: "almost no risk", "slight risk", "moderate risk", "high risk") in alignment to a previous study. ${ }^{27}$

\section{Sociodemographic and diabetes risk factors}

Age was self-reported by participants and sex was recorded by interviewers. General educational graduation (9 categories) and vocational qualification (15 categories) were obtained to categorize educational level into low, middle, and high as previously described. ${ }^{28}$ Diabetes risk factors were assessed as described above.

\section{Preventive healthcare behavior}

Biennial health check-up for early detection of cardiovascular disease, diabetes, and kidney disease is recommended for adults $\geq 35$ years in Germany as 'health check-up 35' by private and statutory health insurance. Participants were asked whether they know this offer by their health insurance. Those answering 'yes' were further asked whether they have ever attended a 'health check-up 35' and whether this has occurred within the last 2 years. Self-reported last blood sugar measurement by a health professional was assessed by the categories 'within last 12 months', 'one to less than 2 years ago', 'two or more years ago', and 'never'.

\section{Information about diabetes risk}

Being informed about an increased diabetes risk by a physician was assessed by asking "Has your physician ever told you that you have an increased diabetes risk?". Whether information about diabetes was obtained by oneself was assessed by the question "Have you ever actively gathered information about diabetes?". An occupational relation to the topic of diabetes was obtained by asking "Are you familiar with diabetes because of your current or former occupation?".

\section{Beliefs on health and diabetes}

Subjective health was assessed by asking "How is your state of health in general?" (response options: "very good", "good", "moderate", "poor", "very poor"). Perception of the seriousness of diabetes was obtained by the question "How serious is diabetes in your view?" (response options: "not serious", "moderately serious", "serious", "very serious", "no opinion") adopted from an earlier study. ${ }^{13}$ Belief in general control of diabetes risk was assessed by the statement "People who make a good effort to control their risk of getting diabetes are much less likely to get diabetes". Belief in personal control was assessed by the statement "I think that my personal efforts could help control my risk of getting diabetes". Participants were asked to indicate their grade of agreement (response options: "fully agree", "agree", "disagree", "fully disagree") to the two previous statements extracted from a personal control subscale. ${ }^{29}$ Perception of the knowledge of diabetes was obtained by the question "How would you rate your knowledge of diabetes?" (response options: "very good", "good", "poor", "absent") in alignment to a previous study.

\section{Statistical analyses}

Analyses were performed using the SAS statistical software package V.9.4 (SAS Institute, Cary, North Carolina, USA) and included a specific weighting factor as previously described. ${ }^{20}$ In brief, this weighting factor corrects for deviations of the study sample from population figures of the Federal Statistical Office with regard to sex, age, federal state of residence, and educational level as of December 31, 2016.

To handle missing values, multiple imputation was applied including perceived risk, all potential determinants, and the weighting factor in the imputation model. Overall, $16.6 \%$ of participants had a missing value in at least one variable and the percentage of missing information per variable ranged from $0.04 \%$ to $5.6 \%$. The authors applied multiple imputation by chained equations $(m=10)$ using the fully conditional specification method assuming an arbitrary pattern of missingness. ${ }^{31}$ Based on the separate imputed data sets, descriptive and logistic regression analyses were performed. Estimates from the individual data sets were then combined according to Rubin's rules taking into account variability within and 
between the imputations. ${ }^{31}$ The level of statistical significance was set at $p$ values $<0.05$ based on two-sided tests.

For descriptive analyses, means (SE) or percentages were calculated and tests for trend across categories of actual diabetes risk were performed using linear or logistic regression. For the subgroup of participants with an elevated or high actual diabetes risk, logistic regression was performed to calculate ORs and 95\% CIs for perceived diabetes risk as dichotomized dependent variable (high/moderate perceived risk vs slight/almost no perceived risk as reference category). Independent variables were all the potential determinants as described above and as operationalized in table 3 and were considered unadjusted in separate models for each determinant as well as mutually adjusted in a multivariable model.

\section{RESULTS}

\section{Actual diabetes risk and characteristics of the study population}

Among the 2327 participants, actual risk to develop diabetes within the next 5 years was low for $59.5 \%$, still low for $16.1 \%$, elevated for $10.4 \%$, and high for $14.1 \%$. As expected according to the score-based definition, persons with a higher actual diabetes risk were older, were more likely to be former smokers, had a higher body mass index (BMI), and more often had a hypertension diagnosis, a family history of diabetes, and low physical activity. In addition, they were more often male and less likely to have a high educational level (table 1).

Of all participants, $37.0 \%$ reported a 'health check-up 35 ' within the last 2 years and $60.7 \%$ reported a blood glucose measurement within the last year; these proportions increased across groups with increasing actual diabetes risk (from $28.0 \%$ to $56.9 \%$ and from $51.6 \%$ to $82.7 \%$, respectively). A total of $6.1 \%$ of participants stated to have been informed by a physician about having an increased diabetes risk and this proportion increased with increasing actual risk (from 3.8\% to $15.3 \%$ ). Overall, $30.3 \%$ stated to have gathered information about diabetes themselves without significant differences across actual risk categories. A total of $18.9 \%$ stated to be familiar with diabetes due to their current or former occupation and this proportion decreased with increasing actual risk (from $22.2 \%$ to $12.9 \%$; table 2 ).

Further, $72.7 \%$ of participants rated their health as very good or good and this proportion decreased with increasing actual risk (from $81.2 \%$ to $53.3 \%$ ). Overall, $65.2 \%$ perceived diabetes as very serious or serious and

Table 1 Sociodemographic and diabetes risk factors across categories of actual diabetes risk among adults without diagnosed diabetes from a nationwide population-based study in Germany $(n=2327)$

\begin{tabular}{|c|c|c|c|c|c|c|}
\hline & \multirow[b]{2}{*}{ Total } & \multicolumn{4}{|c|}{ Categories of actual diabetes risk } & \multirow[b]{2}{*}{$P$ for trend } \\
\hline & & $\begin{array}{l}\text { Low risk } \\
(<2 \%)\end{array}$ & $\begin{array}{l}\text { Still low risk } \\
(2 \% \text { to }<5 \%)\end{array}$ & $\begin{array}{l}\text { Elevated risk } \\
(5 \% \text { to }<10 \%)\end{array}$ & $\begin{array}{l}\text { High risk } \\
(\geq 10 \%)\end{array}$ & \\
\hline $\begin{array}{l}\text { Proportion of study sample } \\
\text { (\%) }\end{array}$ & & 59.5 & 16.1 & 10.4 & 14.1 & \\
\hline \multicolumn{7}{|l|}{ Sociodemographic factors } \\
\hline Sex, male (\%) & 48.6 & 44.6 & 50.0 & 50.4 & 62.4 & $<0.0001$ \\
\hline Age (years) & $51.7(0.6)$ & $41.0(0.6)$ & $63.4(1.0)$ & $69.9(1.0)$ & $70.5(0.9)$ & $<0.0001$ \\
\hline \multicolumn{7}{|l|}{ Educational level (\%) } \\
\hline High & 25.9 & 30.6 & 24.2 & 19.0 & 13.3 & $<0.0001$ \\
\hline Middle & 40.9 & 46.6 & 37.6 & 32.7 & 27.0 & $<0.0001$ \\
\hline Low & 33.2 & 22.9 & 38.2 & 48.3 & 59.7 & $<0.0001$ \\
\hline \multicolumn{7}{|l|}{ Diabetes risk factors } \\
\hline Body mass index $\left(\mathrm{kg} / \mathrm{m}^{2}\right)$ & $25.7(0.1)$ & $23.8(0.1)$ & $26.4(0.3)$ & $27.1(0.3)$ & $31.4(0.4)$ & $<0.0001$ \\
\hline Waist circumference $(\mathrm{cm})$ & $89.8(0.4)$ & $83.1(0.4)$ & $94.6(0.7)$ & $96.8(0.6)$ & $107.7(0.9)$ & $<0.0001$ \\
\hline $\begin{array}{l}\text { Physical activity } \geq 5 \text { hours/ } \\
\text { week }(\%)\end{array}$ & 72.6 & 74.6 & 74.7 & 71.9 & 62.0 & 0.005 \\
\hline \multicolumn{7}{|l|}{ Smoking (\%) } \\
\hline Never & 47.9 & 48.2 & 49.5 & 51.3 & 41.9 & 0.35 \\
\hline Formerly & 25.2 & 21.1 & 26.7 & 27.0 & 39.4 & $<0.0001$ \\
\hline Currently & 26.9 & 30.7 & 23.8 & 21.7 & 18.7 & 0.002 \\
\hline Hypertension diagnosis (\%) & 34.0 & 14.3 & 43.4 & 62.7 & 85.6 & $<0.0001$ \\
\hline $\begin{array}{l}\text { Family history of diabetes } \\
(\%)^{*}\end{array}$ & 22.4 & 17.0 & 22.5 & 34.4 & 36.2 & $<0.0001$ \\
\hline
\end{tabular}

Data are given as weighted mean (SE) or weighted percentage.

${ }^{*}$ At least one parent or sibling with diabetes. 
Table 2 Healthcare behavior, information about diabetes risk, and beliefs on health and diabetes across categories of actual diabetes risk among adults without diagnosed diabetes from a nationwide population-based study in Germany $(n=2327)$

\begin{tabular}{|c|c|c|c|c|c|c|}
\hline & \multirow[b]{2}{*}{ Total } & \multicolumn{4}{|c|}{ Categories of actual diabetes risk } & \multirow[b]{2}{*}{ P for trend } \\
\hline & & $\begin{array}{l}\text { Low risk } \\
(<2 \%)\end{array}$ & $\begin{array}{l}\text { Still low risk } \\
(2 \% \text { to }<5 \%)\end{array}$ & $\begin{array}{l}\text { Elevated risk } \\
(5 \% \text { to }<10 \%)\end{array}$ & $\begin{array}{l}\text { High risk } \\
(\geq 10 \%)\end{array}$ & \\
\hline \multicolumn{7}{|l|}{ Preventive healthcare behavior } \\
\hline \multicolumn{7}{|l|}{$\begin{array}{l}\text { 'Health check-up } 35^{\prime} \text { in last } 2 \\
\text { years (\%) }\end{array}$} \\
\hline Yes & 37.0 & 28.0 & 45.3 & 49.3 & 56.9 & $<0.0001$ \\
\hline No & 14.7 & 12.6 & 18.9 & 20.8 & 14.1 & 0.12 \\
\hline $\begin{array}{l}\text { Don't know this } \\
\text { recommendation }\end{array}$ & 24.0 & 19.1 & 34.7 & 29.9 & 28.3 & 0.0002 \\
\hline $\begin{array}{l}\text { Not relevant as aged below } \\
35 \text { years }\end{array}$ & 24.2 & 40.3 & 1.1 & - & 0.7 & $<0.0001$ \\
\hline \multicolumn{7}{|l|}{$\begin{array}{l}\text { Last blood glucose } \\
\text { measurement (\%) }\end{array}$} \\
\hline Within last 12 months & 60.7 & 51.6 & 66.3 & 74.5 & 82.7 & $<0.0001$ \\
\hline$\geq 1$ year ago & 27.9 & 33.7 & 25.3 & 18.3 & 13.5 & $<0.0001$ \\
\hline Never & 11.4 & 14.7 & 8.4 & 7.2 & 3.8 & 0.0002 \\
\hline \multicolumn{7}{|l|}{ Information about diabetes risk } \\
\hline $\begin{array}{l}\text { Informed from physician } \\
\text { about increased diabetes } \\
\text { risk (\%) }\end{array}$ & 6.1 & 3.8 & 5.4 & 8.1 & 15.3 & $<0.0001$ \\
\hline $\begin{array}{l}\text { Actively informed about } \\
\text { diabetes by oneself (\%) }\end{array}$ & 30.3 & 31.2 & 30.2 & 31.5 & 25.8 & 0.23 \\
\hline $\begin{array}{l}\text { Occupational relation to } \\
\text { diabetes topic (\%) }\end{array}$ & 18.9 & 22.2 & 13.2 & 17.2 & 12.9 & 0.001 \\
\hline \multicolumn{7}{|l|}{ Beliefs on health and diabetes } \\
\hline $\begin{array}{l}\text { Very good or good subjective } \\
\text { health (\%) }\end{array}$ & 72.7 & 81.2 & 67.4 & 58.5 & 53.3 & $<0.0001$ \\
\hline \multicolumn{7}{|l|}{$\begin{array}{l}\text { Perceived seriousness of } \\
\text { diabetes }(\%)\end{array}$} \\
\hline Very serious or serious & 65.2 & 60.9 & 70.1 & 72.4 & 72.1 & 0.001 \\
\hline Moderately or not serious & 22.1 & 25.0 & 21.0 & 14.3 & 16.7 & 0.001 \\
\hline No opinion & 12.7 & 14.0 & 8.9 & 13.3 & 11.2 & 0.38 \\
\hline $\begin{array}{l}\text { Belief in general control of } \\
\text { diabetes risk }(\%)^{*}\end{array}$ & 23.0 & 22.6 & 18.9 & 23.6 & 28.9 & 0.20 \\
\hline $\begin{array}{l}\text { Belief in personal control of } \\
\text { diabetes risk }(\%)^{\star}\end{array}$ & 9.7 & 8.5 & 8.9 & 10.0 & 15.3 & 0.06 \\
\hline $\begin{array}{l}\text { Very good or good perceived } \\
\text { knowledge about diabetes } \\
\text { (\%) }\end{array}$ & 56.4 & 54.0 & 59.1 & 64.2 & 57.8 & 0.12 \\
\hline
\end{tabular}

Data are given as weighted percentage.

‘Based on response 'fully agree' or 'agree'.

this proportion moderately increased with increasing actual risk (from $60.9 \%$ to $72.1 \%$ ). A total of $56.4 \%$ rated their knowledge on diabetes as very good or good, only $23.0 \%$ believed in general control of diabetes risk, and even only $9.7 \%$ believed in personal control; these proportions did not significantly differ across actual risk categories (table 2).
Perceived diabetes risk in relation to actual diabetes risk

Of all participants, the risk to develop diabetes within the next 5 years was perceived as almost absent for $44.3 \%$, as slight for $41.6 \%$, as moderate for $11.8 \%$, and as high for $2.3 \%$. The overall proportion of those who perceived their risk as almost non-existent or slight $(85.9 \%)$ only modestly decreased across groups with 


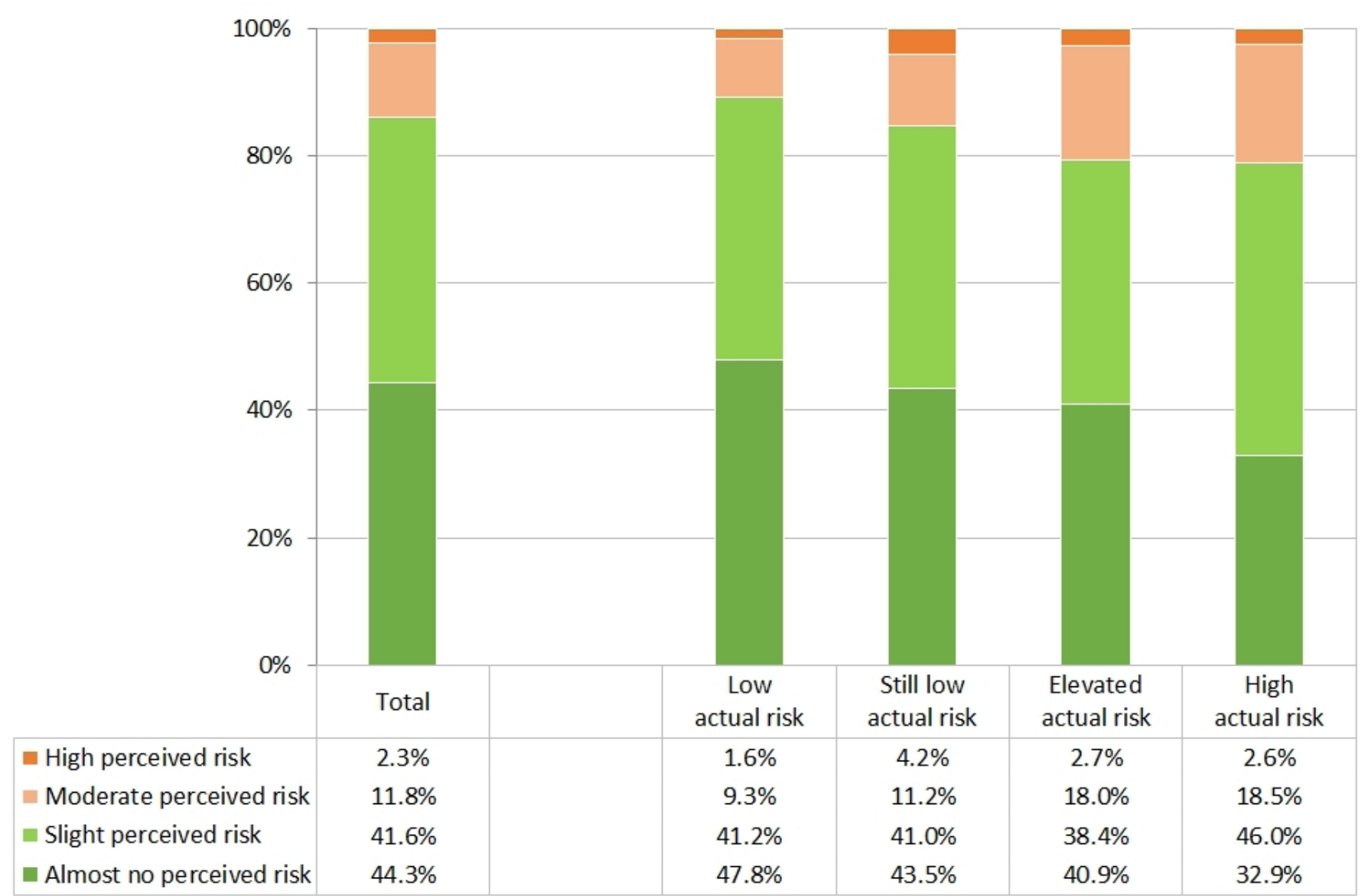

Figure 1 Perceived diabetes risk across categories of actual diabetes risk among adults without diagnosed diabetes from a nationwide population-based study in Germany $(\mathrm{n}=2327)$. Data are given as weighted percentage.

increasing actual diabetes risk (from $89.0 \%$ to $78.9 \%$; figure 1).

\section{Determinants of perceived diabetes risk among adults at increased actual diabetes risk}

In unadjusted logistic regression models focusing on 639 adults with an elevated or high actual diabetes risk, perceiving oneself at increased (ie, moderate or high) diabetes risk was significantly associated with lower age, higher BMI, higher waist circumference, a family history of diabetes, being informed about an increased diabetes risk by a physician, and a poor self-rated health status, whereas perceiving oneself at low (ie, almost no or slight) diabetes risk was significantly related to having no opinion on the seriousness of diabetes. In a multivariable model including all potential determinants, perceiving oneself at increased diabetes risk remained significantly associated with a lower age (OR per year $0.92(95 \%$ CI 0.88 to 0.96$)$ ), a family history of diabetes (2.10 (1.064.16)), and being informed about an increased diabetes risk by a physician (3.27 (1.51-7.07); table 3$)$.

\section{DISCUSSION}

The current nationwide survey showed that overall a relatively low proportion of the adult population perceived their risk to develop diabetes as moderate or high.
This proportion only slightly increased from $10.9 \%$ among those at low actual risk to $21.1 \%$ among those at high actual risk. Focusing on adults with a high or elevated actual diabetes risk revealed that younger age, a family history of diabetes, and being informed about an increased diabetes risk by a physician were strongly related to a higher perceived diabetes risk. In contrast, potentially modifiable risk factors of diabetes, preventive healthcare behaviors, perceived seriousness and knowledge on diabetes as well as beliefs in general and personal control of diabetes risk seemed to play no determining role for perceived risk.

\section{Perceived diabetes risk in relation to actual diabetes risk}

In line with results from the current study, previous studies reported a relatively low proportion of persons that is aware to be at diabetes risk, even if actual diabetes risk defined by a risk score or measured glucose or glycated haemoglobin (HbAlc) values was high. ${ }^{11-1518}$ For example, in a diabetes screening program among elderly residents of the Dutch Hoorn region (1998-2000), 40.1\% of low-risk and $47.9 \%$ of high-risk participants could not give a quantitative estimate (in per cent) of their risk of having diabetes at the moment. Among the remaining persons, mean perceived risk was only slightly higher in those at high actual risk defined by a symptom risk 
Table 3 Association between perceived diabetes risk and potential determinants among adults with an elevated or high actual diabetes risk from a nationwide population-based study in Germany $(n=639)$

\begin{tabular}{|c|c|c|}
\hline & $\begin{array}{l}\text { OR }(95 \% \mathrm{Cl})^{\star} \text { from separate } \\
\text { models for each variable }\end{array}$ & $\begin{array}{l}\text { OR }(95 \% \mathrm{Cl})^{\star} \text { from the fully adjusted } \\
\text { model }\end{array}$ \\
\hline \multicolumn{3}{|l|}{ Sociodemographic factors } \\
\hline Sex (men vs women) & $1.12(0.62$ to 2.03$)$ & $0.66(0.22$ to 1.98$)$ \\
\hline \multicolumn{3}{|l|}{ Educational level } \\
\hline Low & $0.79(0.43$ to 1.45$)$ & $0.87(0.41$ to 1.85$)$ \\
\hline \multicolumn{3}{|l|}{ Diabetes risk factors } \\
\hline Body mass index (per kg/m²) & $1.13(1.07$ to 1.19$)$ & $1.00(0.82$ to 1.20$)$ \\
\hline Waist circumference (per cm) & 1.05 (1.03 to 1.08$)$ & $1.02(0.94$ to 1.11$)$ \\
\hline Formerly & $1.13(0.61$ to 2.10$)$ & 0.85 (0.43 to 1.69$)$ \\
\hline Currently & $1.75(0.76$ to 4.00$)$ & $0.69(0.25$ to 1.89$)$ \\
\hline Hypertension diagnosis (yes vs no) & 0.97 (0.46 to 2.06$)$ & 0.80 (0.37 to 1.73$)$ \\
\hline Family history of diabetes (yes vs no) & 2.57 (1.41 to 4.68$)$ & $2.10(1.06$ to 4.16$)$ \\
\hline \multicolumn{3}{|l|}{ Preventive healthcare behavior } \\
\hline \multicolumn{3}{|l|}{ 'Health check-up 35 ' in last 2 years $\dagger$} \\
\hline Yes & 1 & 1 \\
\hline No & 0.98 (0.47 to 2.08$)$ & 0.84 (0.37 to 1.93$)$ \\
\hline Don't know this recommendation & $0.66(0.30$ to 1.44$)$ & $0.62(0.27$ to 1.47$)$ \\
\hline $\begin{array}{l}\text { Ever actively informed about diabetes by oneself } \\
\text { (yes vs no) }\end{array}$ & 1.59 (0.90 to 2.82$)$ & 1.16 (0.59 to 2.30$)$ \\
\hline Occupational relation to diabetes topic (yes vs no) & $0.88(0.41$ to 1.90$)$ & $0.51(0.22$ to 1.21$)$ \\
\hline \multicolumn{3}{|l|}{ Beliefs on health and diabetes } \\
\hline Subjective health (very good/good vs moderate to poor) & $0.55(0.31$ to 0.98$)$ & $0.52(0.25$ to 1.07$)$ \\
\hline \multicolumn{3}{|l|}{ Perceived seriousness of diabetes } \\
\hline Serious or very serious & 1 & 1 \\
\hline Not or moderately serious & 1.47 (0.74 to 2.89$)$ & $2.02(0.96$ to 4.26$)$ \\
\hline No opinion & $0.31(0.10$ to 0.95$)$ & $0.54(0.16$ to 1.81$)$ \\
\hline $\begin{array}{l}\text { Belief in general control of diabetes risk } \\
\text { (fully agree/agree vs disagree/fully disagree) }\end{array}$ & 1.01 (0.55 to 1.86$)$ & 1.14 (0.50 to 2.58$)$ \\
\hline $\begin{array}{l}\text { Belief in personal control of diabetes risk } \\
\text { (fully agree/agree vs disagree/fully disagree) }\end{array}$ & 0.88 (0.36 to 2.18$)$ & $0.73(0.20$ to 2.71$)$ \\
\hline $\begin{array}{l}\text { Perceived knowledge on diabetes } \\
\text { (very good/good vs poor/very poor) }\end{array}$ & $0.88(0.47$ to 1.63$)$ & $0.58(0.26$ to 1.29$)$ \\
\hline
\end{tabular}

Bold numbers indicate statistically significant ORs ( $p$ value $<0.05$ ).

${ }^{*}$ Calculated based on logistic regression with perceived diabetes risk as dependent variable (high/moderate risk (n(unweighted)=130) vs slight/ almost no risk as reference $(\mathrm{n}($ unweighted $)=509)$ ) and potential determinants as independent variables.

†The category 'not relevant as aged below 35 years' initially comprised only two participants with an elevated/high actual diabetes risk and thus, is excluded from the analysis of the results for this table. 
questionnaire than in those at low actual risk $(10.8 \%$ vs $8.1 \%$ ). The qualitative risk perception question revealed that only $1.9 \%$ of high-risk persons labeled their risk as high or very high. ${ }^{12}$ Among primarily African-American participants in a community-based screening programme in USA $(2003 / 2004)$, the overall proportion of those that believed to be at any diabetes risk $(49 \%)$ was similar to the proportion that scored high at a risk assessment score (44\%). Further, among those with high actual risk, about a third believed to be not at risk of getting diabetes. ${ }^{14}$ In the German cooperative health research in the region of Augsburg (KORA) study comprising residents of the Augsburg region without known diabetes (2013/2014), the proportion that believed to be 'at risk of developing diabetes in the next years' was $14.6 \%$ among those with normal glucose tolerance, $20.6 \%$ among those with impaired glucose tolerance or impaired fasting glucose, and even only $28.7 \%$ among those with a newly detected diabetes. ${ }^{11}$ Similarly, studies that investigated perceived diabetes risk among persons with a history of gestational diabetes or a family history of diabetes also point to an underestimated susceptibility to diabetes development in these high-risk groups. ${ }^{27} 3233$ Furthermore, findings from a repeated telephone survey in USA revealed a stagnant proportion of $\geq 45$-year-olds who believed to be at risk for diabetes or prediabetes from 2006 to 2011 and this proportion was at a low level for those defined to be at risk for diabetes and at a moderate level for those with prediabetes. $^{19}$

\section{Determinants of perceived diabetes risk among adults at increased actual diabetes risk}

Determinants of the discrepancy between perceived and actual risk have been scarcely investigated for high-risk individuals. In agreement with our findings, the Dutch study in the Hoorn region, a subsample of the Dutch study that was recontacted after several years, and the German KORA study have consistently shown that a family history of diabetes and lower age are associated with a higher perceived risk in adults at high actual diabetes risk, even after multivariable adjustment. ${ }^{11} 1218$ Possible explanations for the inverse association between age and perceived risk were that older people may think that if they were susceptible to diabetes, they would have already developed $i^{18}$ or that older people may have less knowledge about diabetes and risk factors than younger people. ${ }^{12}$ Potentially modifiable risk factors of diabetes such as physical inactivity, unhealthy diet, high BMI, and hypertension were not or not consistently related to a higher perceived diabetes risk. ${ }^{11} 1218$ Similarly, we found no significant association of physical inactivity, smoking, or hypertension with perceived risk and the direct association between BMI und perceived risk diminished in multivariable analysis. Interestingly, in the KORA study, a higher educational level and poor subjective health were related to a higher perceived risk. ${ }^{11}$ While we obtained a similar result regarding subjective health in the unadjusted analysis, this association was no longer significant in multivariable analysis. Further, we did not observe any association with education. A study among women with a history of gestational diabetes even found that those with a high risk perception had less education than those with a low risk perception. ${ }^{27}$ It can be assumed that the operationalization of education and selection criteria of the study participants may play a role for these divergent results; for example, while mostly lower-educated older men and women (mean age: 59.1 years) were included in the KORA study, ${ }^{11}$ the study among women with a history of gestational diabetes comprised mostly well-educated younger women (35.7 years) ${ }^{27}$ Among the range of additional available factors in the current study, being informed about one's increased diabetes risk by a physician emerged as the only, but strong determinant of perceived diabetes risk. This result illustrates the importance of strengthening the healthcare system to enable physicians to implement primary prevention in daily practice. ${ }^{34}$ Based on their medical expertise, physicians could then assess a patient's risk profile, comprehensively communicate an elevated risk ${ }^{35}$ and, in a dialog, further provide decision aids to improve patient's knowledge and comfort regarding available options for lifestyle changes according to the personal daily life context. ${ }^{36}{ }^{37}$ Thereby, physicians can provide an essential contribution to effective risk communication and maintained behavioral modifications.

\section{Public health relevance and practical implications}

The public health relevance of the findings is based on the massive burden of prediabetes in many countries. ${ }^{34}$ In Germany, $20.8 \%$ of the people aged $18-79$ years (13.1 million) have HbAlc-defined prediabetes. ${ }^{28}$ In line with this estimate, $24.5 \%$ of adults aged $\geq 18$ years were identified to be at increased diabetes risk based on an established risk score in the current study, which represent a considerable proportion of the population as a potential target group for primary prevention. However, in contrast to the available evidence on risk factors of diabetes, ${ }^{1}$ high-risk individuals of the current and previous studies did not or only barely link their prevailing modifiable risk factors with an increased perceived risk and ageing was even inversely linked with perceived risk. Thus, primary prevention approaches should include measures that increase the awareness of diabetes risk factors such as unhealthy lifestyle behaviors and ageing in the general public and improve patient education by health professionals with regard to prevailing personal risk factors. Application of multifactorial risk assessment scores could serve as a supporting tool in such awareness strategies.

According to health behavioral theories, an increased perceived risk for a disease is a prerequisite for preventive action, but needs to be supported by other components of precautionary behavior. ${ }^{9} 1038$ Behavioral changes seem to be more likely if the awareness of disease risk is prompted in conjunction with an increased awareness of disease severity or enhancing the control beliefs about disease-related risk factors. ${ }^{10} 3839$ While the proportion of 
adults that acknowledged diabetes as a serious condition was relatively high in the current study (overall 65.2\%), the proportions of adults that believed in general or personal control of diabetes risk (overall $23.0 \%$ or $9.7 \%$ ) were surprisingly low. Thus, strengthening control beliefs also appears to be essential in diabetes prevention strategies, for example, by emphasizing the potential of lifestyle recommendations for prevention of diabetes development and advising people on lifestyle changes and how to specifically implement and maintain them.

\section{Limitations}

Actual diabetes risk was not defined by an objective assessment of glucose parameters as in a previous study, ${ }^{11}$ but by using a non-laboratory diabetes risk score. However, while glucose measurements at a single point in time have own inherent limitations, ${ }^{40}$ the applied multifactorial score is an established tool for predicting type 2 diabetes risk $^{22}$ and previous validation of the used simplified score version reflected an excellent predictive ability. ${ }^{24}$ In addition, the proportion of adults with an elevated or high diabetes risk that was calculated based on the risk score in the current study is in good agreement with a previously reported prevalence of HbAlc-defined prediabetes in Germany. ${ }^{28}$ Still, due to the telephone interview mode, all data on score components were of self-reported nature and thus, misclassification may have occurred. In addition, actual diabetes risk was calculated quantitatively as absolute risk in per cent, whereas perceived diabetes risk was assessed qualitatively based on a four-categorical response option. These different scales and the subsequent categorizations for analyses could have led to false cross-classifications. Further, the response rate of the survey was relatively low. To adjust for deviations of survey participants with respect to certain characteristics (age, sex, federal state of residence, educational level) from the German resident population aged at least 18 years, a complex weighting factor ${ }^{20}$ was used throughout our analysis. However, despite the weighting procedure, a selection bias due to non-response cannot be entirely excluded. In particular, non-responders may differ from survey participants in terms of other characteristics of major interest to the current study and these differences may have biased our results. Finally, the moderate sample size of persons with an elevated or high actual risk in regression models may have led to dismissing existing determinants of perceived risk.

\section{CONCLUSIONS}

The current nationwide data reflect a relatively low perception of diabetes risk in the general adult population in Germany, even if actual diabetes risk measured by a multifactorial risk score is high. Findings of this study could inform the strategic orientation of prevention strategies on diabetes by emphasizing the need to increase the awareness and control beliefs about diabetes risk and by pointing out the importance of effective risk communication with health professionals in high-risk groups.

Contributors $\mathrm{CH}, \mathrm{RP}, \mathrm{LMS}, \mathrm{DZ}, \mathrm{PG}$ and CS-N conceptualized the survey. $\mathrm{CH}$ defined the analytic strategy, analyzed the data and drafted the manuscript. RP and JB supported statistical modeling. All authors critically revised the manuscript for important intellectual content and read and approved the final version of the manuscript.

Funding The study "Disease knowledge and information needs - Diabetes mellitus (2017)" was funded by the Federal Ministry of Health (Funding Code: GE20160358).

Competing interests None declared.

Patient consent for publication Not required.

Ethics approval The study was approved by the ethics committee of Berlin's Chamber of Physicians (No: Eth-23/17) and the Federal Commissioner for Data Protection and Freedom of Information.

Provenance and peer review Not commissioned; externally peer reviewed.

Data sharing statement Data are available upon reasonable request.

Open access This is an open access article distributed in accordance with the Creative Commons Attribution Non Commercial (CC BY-NC 4.0) license, which permits others to distribute, remix, adapt, build upon this work non-commercially, and license their derivative works on different terms, provided the original work is properly cited, appropriate credit is given, any changes made indicated, and the use is non-commercial. See: http://creativecommons.org/licenses/by-nc/4.0/.

\section{REFERENCES}

1. Zheng Y, Ley SH, Hu FB. Global aetiology and epidemiology of type 2 diabetes mellitus and its complications. Nat Rev Endocrinol 2018;14:88-98.

2. Hu FB, Satija A, Manson JE. Curbing the diabetes pandemic: the need for global policy solutions. JAMA 2015;313:2319-20.

3. International Diabetes Federation. Chapter 3: The global picture. In: IDF diabetes atlas. 8th edn. Brussels, Belgium, 2017: 40-65.

4. Tabák AG, Herder C, Rathmann W, et al. Prediabetes: a high-risk state for diabetes development. The Lancet 2012;379:2279-90.

5. Centers for Disease Control and Prevention. National diabetes statistics report. 2017. US department of health and Human services. Atlanta, GA. Available: https://www.cdc.gov/diabetes/data/ statistics/statistics-report.html [Accessed March 2019].

6. World Health Organisation. Part 2: preventing diabetes. Global report on diabetes. Geneva World Health Organization; 2016: 34-45. http:// apps.who.int/iris/bitstream/handle/10665/204871/9789241565257_ eng.pdf;jsessionid=3263530A34BD3CE67600D37307290269? sequence $=1$

7. Ibrahim M, Tuomilehto J, Aschner P, et al. Global status of diabetes prevention and prospects for action: a consensus statement. Diabetes Metab Res Rev 2018;34:e3021.

8. Haw JS, Galaviz KI, Straus AN, et al. Long-term sustainability of diabetes prevention approaches: a systematic review and meta-analysis of randomized clinical trials. JAMA Intern Med 2017;177:1808-17.

9. Pligt J. Perceived risk and vulnerability as predictors of precautionary behaviour. Br J Health Psychol 1998;3:1-14.

10. Sheeran $P$, Harris PR, Epton T. Does heightening risk appraisals change people's intentions and behavior? A meta-analysis of experimental studies. Psychol Bull 2014;140:511-43.

11. Kowall B, Rathmann W, Stang A, et al. Perceived risk of diabetes seriously underestimates actual diabetes risk: the KorA FF4 study. PLoS One 2017;12:e0171152.

12. Adriaanse MC, Twisk JWR, Dekker JM, et al. Perceptions of risk in adults with a low or high risk profile of developing type 2 diabetes; a cross-sectional population-based study. Patient Educ Couns 2008;73:307-12.

13. Adriaanse MC, Snoek FJ, Dekker JM, et al. Perceived risk for type 2 diabetes in participants in a stepwise population-screening programme. Diabet Med 2003;20:210-5.

14. Graham GN, Leath $B$, Payne $K$, et al. Perceived versus actual risk for hypertension and diabetes in the African American community. Health Promot Pract 2006;7:34-46.

15. Yang K, Baniak LM, Imes CC, et al. Perceived versus actual risk of type 2 diabetes by race and ethnicity. Diabetes Educ 2018;44:269-77.

16. Godino JG, van Sluijs EMF, Sutton S, et al. Understanding perceived risk of type 2 diabetes in healthy middle-aged adults: a 
cross-sectional study of associations with modelled risk, clinical risk factors, and psychological factors. Diabetes Res Clin Pract 2014;106:412-9.

17. Hivert M-F, Warner AS, Shrader P, et al. Diabetes risk perception and intention to adopt healthy Lifest yles among primary care patients. Diabetes Care 2009;32:1820-2.

18. Claassen L, Henneman L, Nijpels G, et al. Causal beliefs and perceptions of risk for diabetes and cardiovascular disease, the Netherlands, 2007. Prev Chronic Dis 2011;8.

19. Piccinino L, Griffey S, Gallivan J, et al. Recent trends in diabetes knowledge, perceptions, and behaviors: implications for national diabetes education. Health Educ Behav 2015;42:687-96.

20. Paprott R, Heidemann C, Stühmann L, et al. First results from the study „Disease knowledge and Information needs - Diabetes mellitus (2017)". Journal of Health Monitoring 2018;3:22-60.

21. American Association for Public Opinion Research. Standard Definitions - Final Dispositions of Case Codes and Outcome Rates for Surveys, 2016. Available: https://www.aapor.org/AAPOR_Main/ media/publications/Standard-Definitions20169theditionfinal.pdf [Accessed April 2019].

22. Schulze MB, Hoffmann $\mathrm{K}$, Boeing $\mathrm{H}$, et al. An accurate risk score based on anthropometric, dietary, and lifestyle factors to predict the development of type 2 diabetes. Diabetes Care 2007;30:510-5.

23. Mühlenbruch $\mathrm{K}$, Joost $\mathrm{HG}$, Boeing $\mathrm{H}$, et al. Risk prediction for type 2 diabetes in the German population with the updated German diabetes risk score (GDRS). Ernaehrungs Umschau 2014;61:90-3.

24. Paprott R, Mühlenbruch K, Mensink GBM, et al. Validation of the German diabetes risk score among the general adult population: findings from the German health interview and examination surveys. BMJ Open Diabetes Res Care 2016;4:e000280.

25. Scheidt-Nave C, Kamtsiuris P, Gößwald A, et al. German health interview and examination survey for adults (DEGS) - design, objectives and implementation of the first data collection wave. BMC Public Health 2012;12.

26. German Institute of Human Nutrition Potsdam-Rehbruecke. German Diabetes Risk Score - Personal Test. Available: http://www.dife. de/diabetes-risiko-test/DIfE_Privatperson_2014_en_PRINT.pdf [Accessed March 2019].

27. Kim C, McEwen LN, Piette JD, et al. Risk perception for diabetes among women with histories of gestational diabetes mellitus. Diabetes Care 2007;30:2281-6.

28. Heidemann C, Du Y, Paprott R, et al. Temporal changes in the prevalence of diagnosed diabetes, undiagnosed diabetes and prediabetes: findings from the German health interview and examination surveys in 1997-1999 and 2008-2011. Diabet Med 2016;33:1406-14.

29. Walker EA, Mertz CK, Kalten MR, et al. Risk perception for developing diabetes: comparative risk judgments of physicians. Diabetes Care 2003;26:2543-8.

30. Wright Nunes JA, Wallston KA, Eden SK, et al. Associations among perceived and objective disease knowledge and satisfaction with physician communication in patients with chronic kidney disease. Kidney Int 2011;80:1344-51.

31. Berglund PA. Multiple Imputation Using the Fully Conditional

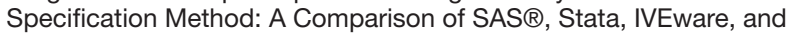
R. Paper 2081-2015 [Internet]. Available: http://support.sas.com/ resources/papers/proceedings15/2081-2015.pdf [Accessed Sept 2018].

32. Dorman JS, Valdez R, Liu T, et al. Health beliefs among individuals at increased familial risk for type 2 diabetes: implications for prevention. Diabetes Res Clin Pract 2012;96:156-62.

33. Harwell TS, Dettori N, Flook BN, et al. Preventing type 2 diabetes: perceptions about risk and prevention in a populationbased sample of adults $>$ or $=45$ years of age. Diabetes Care 2001;24:2007-8.

34. Härter M, Dirmaier J, Scholl I, et al. The long way of implementing patient-centered care and shared decision making in Germany. Zeitschrift für Evidenz, Fortbildung und Qualität im Gesundheitswesen 2017;123-124:46-51.

35. Gigerenzer G, Edwards A. Simple tools for understanding risks: from innumeracy to insight. BMJ 2003;327:741-4.

36. Stacey D, Légaré F, Lewis K, et al. Decision aids for people facing health treatment or screening decisions. Cochrane Database Syst Rev 2017;4.

37. Rodriguez-Gutierrez R, Gionfriddo MR, Ospina NS, et al. Shared decision making in endocrinology: present and future directions. Lancet Diabetes Endocrinol 2016;4:706-16.

38. Ruiter RAC, Kessels LTE, Peters G-JY, et al. Sixty years of fear appeal research: current state of the evidence. Int J Psychol 2014;49:63-70.

39. Brewer NT, Chapman GB, Rothman AJ, et al. Increasing vaccination: putting psychological science into action. Psychol Sci Public Interest 2017;18:149-207.

40. Selvin E, Crainiceanu CM, Brancati FL, et al. Short-term variability in measures of glycemia and implications for the classification of diabetes. Arch Intern Med 2007;167:1545-51. 